\title{
Do Português ao Italiano: REFlexões PaRa ElaboraÇÃo De um Dicionário Pedagógico Voltado para a Produção
}

Paola Baccin

RESUMO O presente trabalho apresenta as reflexões para a elaboração de um dicionário pedagógico bilíngüe (português - italiano) em formato eletrônico, de acesso gratuito, com vistas à produção de textos em língua italiana. Denominado Cantiere di parole (Canteiro de palavras), oprojeto reúne o resultado de pesquisas de lexicógrafos da USP e daUNESP - SJRP que, há alguns anos, se dedicam ao estudo da problemática relativa ao uso de dicionários, ao tratamento dos diversos campos léxico-semânticos e às dificuldades e necessidades específicas dos alunos brasileiros de língua italiana no campo da aprendizagem do léxico.

PALAVRAS-CHAVE lexicografia pedagógica; dicionário bilíngüe; língua italiana. 
ABSTIRACT In questo lavoro sono presentate alcune riflesssioni per l'elaborazione di un dizionario pedagogico bilingue (portoghese - italiano) in formato elettronico, di accesso gratuito, per la produzione di testi in lingua italiana. Col titolo Cantiere di parole, il progetto riunisce i risultati di ricerche di lessicografi della USP e dell'UNESPSJRP che, da alcuni anni, si dedicano allo studio della problematica riguardante l'uso di dizionari, il trattamento dei diversi campi lessico-semantici e le difficoltà e necessità specifiche degli studenti brasiliani di lingua italiana nel campo dell'apprendimento del lessico.

PAROLE CHIAVE lessicografia pedagogica; dizionario bilingue; lingua italiana.

ABSTRAC'1 The current paper presents thoughts to pull together a free bilingual learner's dictionary (Portuguese-Italian) in electronic media designed for text production in Italian. Called Cantiere di parole (word worksite), the project gathers the research findings of lexicographers from USP and UNESP - SJRP who have dedicated years to studying the problem of using dictionaries, the treatment given to various lexical-semantic fields and the difficulties and specific needs of Brazilian students of Italian as regards lexical assimilation.

KEYWOKDS teaching lexicography, bilingual dictionary, Italian language. 


\section{Introdução e histórico}

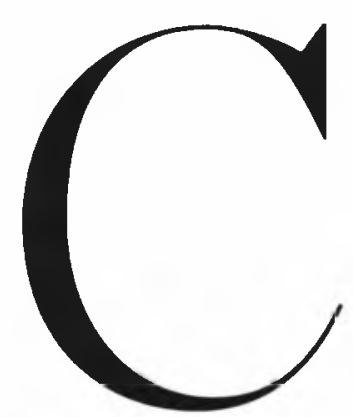

antiere diparole (canteiro de palavras) é um projeto que reúne o resultado de trabalhos de lexicógrafos que, há alguns anos, se dedicam ao estudo da problemática relativa ao uso de dicionários, ao tratamento dos diversos campos léxico-semânticos e às dificuldades e necessidades específicas dos alunos brasileiros de língua italiana no campo da aprendizagem do léxico. Desde a sua constituição, foram realizadas diversas pesquisas entre as quais destacamos a pesquisa sobre o público-alvo, os alunos de língua italiana dos cursos de graduação e dos cursos livres da Universidade de São Paulo (Baccin, et alii: 2004) e a análise dos dicionários usados pelos alunos de língua italiana (Baccin, et alii: 2005). Em 2007, dois alunos de Iniciação Científica, sob nossa orientação, dedicaram-se ao estudo de alguns campos léxico-semânticos e sua possibilidade de tratamento dentro de um dicionário para aprendizes. Flávio Soares Júnior (que prosseguirá sua pesquisa sob orientação da professora Roberta Barni) faz um estudo das unidades lexicais dos links utilizados nas páginas dos cursos online de língua italiana para estrangeiros e seus equivalentes em português brasileiro, com vistas à elaboração de um modelo de glossário; Jéssica Lima e Silva elaborou uma metodologia com base em questionários e análise de produções escritas de alunos. A metodologia foi testada com o campo das vestimentas e poderá ser aplicada aos demais campos léxico-semânticos tais como: alimentação e refeições; casa e mobiliário; mobiliário urbano; meios de transporte etc.

Fazem parte da equipe os seguintes pesquisadores da USP: Roseli Dornelles (mestranda) estuda a problemática relativa aos verbos reflexivos e pronominais, centrando a discussão na própria denominação (em italiano e seu correspondente em português); Ana Paula de Souza (graduada) elabora um projeto de mestrado que estuda a problemática relativa aos adjetivos e pronomes in- 
definidos; Daniel Ferreira Martins Neto (graduando) elabora um projeto de iniciação científica e TGI sobre o campo léxico-semântico relativo às refeições e aos alimentos; Alessandra Caramori desenvolveu, para seu trabalho de doutorado, defendido em 2007, uma metodologia para a inclusão e o tratamento das expressões idiomáticas em um dicionário pedagógico e Angela Zucchi estuda a inclusão e o tratamento das colocações em um dicionário pedagógico. Da UNESP de São José de Rio Preto, participam da equipe duas pesquisadoras que agregaram ao grupo os resultados das pesquisas que vêm realizando há muitos anos. Claudia Zavaglia elaborou uma metodologia de elaboração de verbetes multilingües para o campo léxico-semântico das cores. Além disso, estuda, atualmente, a problemática da inserção da linguagem erótico-obscena nos dicionários. Marilei Sabino estudou o tratamento especial às unidades lexicais que se apresentam, aos consulentes e/ou aprendizes brasileiros, como "falsos cognatos" ou "cognatos enganosos" em relação à língua italiana.

Este artigo tem como escopo apresentar, de forma concisa, as reflexões realizadas desde a certificação do Grupo de Pesquisa que possibilitaram o encaminhamento do projeto para a sua segunda fase.

\section{Tipologia e denominações dos dicionários}

A tentativa de classificar dicionários de modo tal que a classificação seja aplicável a todas as sociedades é infrutífera (Béjoint, 2000:37). De fato, as pesquisas em lexicografia e metalexicografia revelam que a ciência de fazer dicionários é mais complexa do que se supunha. Deve-se conhecer a evolução dos estudos na área e analisar as obras existentes para empreender a tarefa de elaborar mais uma obra lexicográfica.

Procuramos aqui sistematizar, de maneira sucinta, as definições que serviram para orientar as nossas reflexões com base nas pesquisas de levantamento de dados de Duran (2004), Humblé (2006), Welker (2006) e Tarp (2006).

O dicionário monolíngüe é aquele que apresenta uma única língua e cujo público-alvo é o falante nativo, enquanto o dicionário bilíngüe apresenta duas línguas em contato. Santos (2006: 23) acrescenta, como característica própria de cada dicionário, a presença ou não de definição. Enquanto o primeiro "apresenta a explicação da entrada em forma de uma definição na mesma língua do lema", no segundo "a explicação é fornecida na forma de um equivalente, ou uma série de equivalentes na língua meta"

Humblé, 2007 (no prelo), comenta:

A secreta opinião pública é que estes dicionários são feitos por sujeitos bilíngües que, fazendo uma seleção nos dicionários monolíngües, traduzem as palavras mais 
comuns. Há dicionários bilíngües melhores que outros. Mas todos têm, mesmo para o leigo, falhas: o verbete é longo e só traz uma lista de palavras traduzidas sem explicação; falta 'exatamente' a palavra que se procurava; abundam as crípticas abreviaturas. Ao querer dizer alguma coisa na língua estrangeira, o dicionário sempre sugere uma palavra logo censurada pelo falante nativo ou o professor: "neste caso, diz ele, não falaríamos assim...”. São poucos os dicionários bilíngües que contam com a irrestrita aprovação do usuário.

Quanto ao público alvo, o dicionário bilíngüe pode ser não-recíproco (destinado aos falantes de uma língua: língua materna em contato com uma língua estrangeira) ou recíproco (atender aos falantes das duas línguas em contato, no qual as funções de língua materna e língua estrangeira alternam-se de acordo com os usuários). Pode servir de apoio para a decodificação (da língua estrangeira para a língua materna) ou para a codificação (da língua materna para a língua estrangeira) ou ser bidirecional, servindo de apoio à codificação e à decodificação (Duran, 2004).

Há ainda uma terceira modalidade. Os dicionários semibilíngües (DSB), também chamados de monolíngües com equivalente, ou híbridos, que incluem exemplos e definições em língua estrangeira, além dos equivalentes e da tradução em língua materna. ${ }^{1}$

Para o italiano, temos, nessa modalidade, o dicionário Parola Chiave. Dizionario di italiano per brasiliani ${ }^{2}$. A apresen tação do dicionário especifica o público alvo - os estudantes brasileiros -, apresenta a metodologia de sua execução, bem como os critérios de elaboração dos verbetes:

Os termos para os quais não existem equivalentes brasileiros (...) foram conservados em italiano, mas grafados em itálico e negrito. As palavras intraduziveis - em sua maioria preposições empregadas no italiano em regências verbais e nominais inexistentes em português - estão indicadas por $\emptyset$.

A terminologia relativa à lexicografia pedagógica tem-se afirmado a cada dia, com base na publicação de novas pesquisas e da sistematização de sua relativa bibliografia. A esse respeito remetemos ao trabalho de Welker e Humblé (2006).

Sven Tarp (2006) discute as características de um dicionário para aprendizes e define dicionário pedagógico ${ }^{3}$ como:

un diccionario cuyo objetivo genuino es el de satisfacer las necesidades de información lexicograficamente relevantes que tengan los etudiantes en una serie de situaciones extra-lexicográficas durante el proceso de aprendizaje de una lengua extranjera. (Tarp apud Tarp, 2006:300)

1. Para uma discussão mais aprofundada sobre a terminologia e, principalmente, sobre a modalidade semibilíngüe cf. Duran, 2004. pp. 54 e ss. 2. Martins Fontes, São Paulo: 2007.

3. Quanto à terminologia optamos por dicionário pedagógico, também para a tradução de dicionário de aprendizaje ou learner's dictionary (usados no original, em espanhol, pelo autor). 
O autor afirma que, apesar de a Lexicografia Pedagógica ter uma história de mais de 70 anos e de possuir um objeto específico de estudo, que é também um produto cultural e historicamente determinado - o dicionário para aprendizes -, somente há pouco tempo estudiosos têm-se dedicado ao desenvolvimento de uma teoria geral da Lexicografia Pedagógica. Cita como "embriões" de uma teoria geral sobre esse campo os estudos de Scerba (1940), Hausman (1977), Wiegand (1977 e 1998) e Bergenholtz e Tarp (2002, 2003 e 2005).

\section{Proposta de elaboração de um dicionário pedagógico para aprendizes brasileiros de italiano como língua estrangeira}

\subsection{Público usuário}

O público usuário ao qual nos dedicamos é o aprendiz brasileiro de língua italiana como língua estrangeira. Há dois tipos de aprendizes, os que desejam aprender a língua como usuários, apenas para comunicar-se em italiano, e os que desejam aprender a língua como usuários, mas, também, com o objetivo de empregá-la como ferramenta de trabalho.

Denominamos, portanto, aprendiz-especialista, o aluno que pretende usar o idioma como ferramenta de trabalho: o aluno que freqüenta os cursos de graduação em língua italiana nas Universidades brasileiras, cujo objetivo é tornar-se um profissional em lingua italiana (bacharelado ou licenciatura).

Algumas pesquisas foram realizadas para conhecer esse público. Ivy Sene (2004) e Jéssica Silva de Lima (2007), alunas de Iniciação Científica (FFLCH - USP), realizaram, sob nossa orientação, questionários para analisar a relação entre os alunos dos cursos de graduação e os dicionários escolhidos por eles ou indicados pelos professores. Percebemos, no entanto, que a metodologia utilizada permitiu que compreendêssemos, apenas de maneira parcial, as necessidades do nosso público e sua relação com o(s) dicionário(s). Acreditamos que uma contribuição nesse sentido poderia vir da aplicação da metodologia usada no estudo de crenças de professores em formação inicial e em serviço desenvolvida pela professora Ana Maria Ferreira Barcelos $(1995,2001,2006)$. Essa metodologia prevê, além de questionários elaborados de maneira criteriosa, entrevistas, auto-relatos, observação de aulas, notas de campo e diários, gravações em áudio e vídeo e sessões de visionamento (Abrahão: 2006). 
Em conclusão, o público ao qual o nosso trabalho é dirigido é o aluno de língua italiana cujo objetivo é aprender a língua para fins de trabalho com o idioma, com ênfase nos alunos dos niveis iniciais e intermediários do curso.

\subsection{Dicionário para a produção ou para a compreensão}

Definido o público usuário - o aprendiz-especialista -, cabe decidir qual a direção do dicionário, do italiano para o português ou do português para o italiano, ou optar pela proposta mais ambiciosa, criando um dicionário bidirecional.

$\mathrm{Na}$ aula de língua, o professor conta com várias ferramentas, mas duas têm caráter mais permanente e exigem um investimento financeiro mais significativo por parte dos alunos: o livro didático e o dicionário.

O dicionário é a ferramenta que conduz o aluno à autonomia e é fundamental para a compreensão e a produção de textos em uma língua estrangeira. Dicionários monolíngües, editados no exterior, são volumosos e de custo elevado para a maioria dos nossos alunos. Os dicionários publicados no Brasil não são específicos para a produção de textos de aprendizes em língua italiana, uma vez que visam, em primeiro lugar, proporcionar a compreensão e auxiliar os tradutores de textos italianos. Pesquisas metalexicográficas concluíram que os dicionários bilingües (italiano-português), elaborados principalmente para tradutores e para o público em geral, não levam em consideração os princípios da lexicografia pedagógica. No entanto, o público usuário desses dicionários é formado, em grande parte, por estudantes de italiano como lingua estrangeira.

Para o público em geral, para os profissionais da língua italiana, para o aluno já formado e que atua no mercado de trabalho como especialista, professor, tradutor, pesquisador, há uma grande variedade de excelentes dicionários monolíngües ou bilíngües resultado de longa tradição lexicográfica.

Até há pouco tempo, o aluno contava apenas com os textos publicados nos livros didáticos como suporte para a aprendizagem. Os textos eram construídos artificialmente de modo a incluir um léxico controlado ou textos autênticos eram didatizados, compreendendo-se por didatização a simplificação e eventual inserção de glossários de palavras novas. Hoje, a facilidade de importação de material e, principalmente, o acesso à Internet permitem que o professor e os alunos tenham em mãos uma ampla tipologia de material autêntico.

Um paralelo pode ser traçado para o uso do dicionário como suporte ao processo de ensino e aprendizagem. Alguns anos atrás, o aluno contava apenas com o dicionário de bolso para ajudá-lo na compreensão e na produção textual. Hoje, a Internet permite que o estudante pesquise o contexto das palavras novas e descubra, pelo estudo autônomo, significados e possibilidades de sentido, imagens e até a pronúncia das unidades lexicais. O papel do professor mudou radicalmente 
diante da mudança nas possibilidades de escolhas de material. Hoje, tem-se somente "l'imbarazzo della scelta". E as dúvidas acumulam-se diante de uma possibilidade infinita de escolhas.

No sentido da compreensão textual o aluno conta com várias ferramentas, inclusive em formato eletrônico, como dicionários monolíngües, dicionários semi-bilíngües, motores de busca na Internet. No sentido da produção textual, no entanto, há uma lacuna e é nessa direção que acreditamos poder contribuir com a elaboração de um dicionário específico para a produção de textos em língua italiana.

O dicionário não é o substituto do livro didático, mas é uma ferramenta pedagógica de consulta. Encontramos no comércio diversos dicionários que auxiliam o aluno na compreensão dos textos. Sabe-se que, durante o curso, são apresentadas aos alunos tipologias textuais diversas e, cada vez mais, se recorre a textos autênticos. Assim sendo, na direção da compreensão, sugerimos para os alunos os dicionários monolíngües ou semibilíngües já publicados que ajudam o aluno a aumentar o seu repertório lingüístico por meio da leitura e compreensão das definições e dos exemplos.

Para a produção, no entanto, não há obras específicas destinadas ao nosso público-alvo. O aluno incorre em muitos erros de escolha lexical do português para o italiano, ao consultar o dicionário, mesmo tendo recebido orientações para a consulta. ${ }^{4}$

A metodologia desenvolvida pela aluna Jéssica Lima Silva comprova que as diferenças relativas ao extralingüístico e suas denominações nas duas culturas em contato não são resolvidas apenas buscando no acervo lexicográfico italiano os correspondentes em português, pois a freqüência e as marcas de uso não correspondem. Ao iniciarmos a pesquisa, estudamos o dicionário como recurso à compreensão textual e optamos por dois livros didáticos de italiano para estrangeiros (Linea Diretta e Rete) dos quais tiraríamos os contextos e as unidades lexicais para o nosso dicionário. Logo, o procedimento mostrou-se infrutífero porque os contextos não eram claros, há muitas unidades lexicais isoladas em exercícios e um dicionário de compreensão baseado nesse critério não seria útil ao aluno por vários motivos. Sob nossa orientação, a aluna de iniciação científica comprovou esse fato ao usar essa metodologia para estudar o campo léxico das vestimentas e concluiu que as unidades lexicais extraídas dos livros didáticos não são suficientes para que o aluno compreenda a árvore conceitual desse campo.

Na direção da produção, Jéssica Silva de Lima aplicou um questionário, em língua portuguesa, sobre as vestimentas usadas pelos alunos em algumas ocasiões (em casa, no trabalho, no verão, no inverno). O objetivo era descobrir o vocabulário mínimo de interesse dos estudantes. Essa metodologia mostrou-se adequada para começar a estabelecer a escolha do repertório lexical. $\mathrm{O}$ questionário foi ampliado, corrigido e adaptado para outros campos semânticos como a alimentação, a casa, as profissões, defeitos, qualidades e outros adjetivos.

4. Uma pesquisa no sentido de verificar com dados científicos essa problemática está sendo desenvolvida pela Professsora Ângela Zucchi (USP). 


\subsection{Macro e microestrutura}

O projeto tem como objetivo geral propor uma ferramenta lexicográfica gratuita de consulta online aos alunos de língua italiana para a produção de textos. Como objetivos específicos: 1. fazer um levantamento das dificuldades relativas ao léxico no momento da produção de textos em língua italiana, específicas do aluno brasileiro; 2. propor soluções lexicográficas específicas para os alunos de língua italiana; 3 . propor soluções lexicográficas específicas para os diferentes campos léxico-semânticos; 4 contribuir para as pesquisas na área da lexicografia pedagógica, principalmente no formato eletrônico.

A metodologia empregada é fruto das reflexões e estudos realizados pelos pesquisadores envolvidos no projeto. Alguns campos léxico-semânticos já foram pesquisados e sua metodologia testada e apresentada como resultado de trabalhos de mestrado e de doutorado. Outros campos léxico-semânticos estão sendo estudados e, para cada um deles, será elaborada uma metodologia específica. Dai a importância da reunião de todos esses pesquisadores no projeto. À medida que cada pesquisador reunir um conjunto de unidades lexicais, passaremos ao tratamento e à uniformização para sua publicação on line. O dicionário será alimentado ao longo dos três anos de duração do projeto e testado pelos usuários durante esse periodo. O suporte eletrônico e conseqüente interação com o consulente permitirão verificar a eficácia dos dados, das escolhas lexicográficas e realizar os ajustes necessários.

O dicionário pedagógico com vistas à produção tem duas funções primordiais que devem receber um tratamento adequado, de forma que uma não prejudique a outra:

1. Responder de maneira imediata às dúvidas e lacunas de léxico com que o aluno se depara durante a produção de um texto. A consulta ao dicionário deve ser rápida para não prejudicar o fluxo do pensamento.

2. O caráter pedagógico permite também um tratamento enciclopédico dos dados do dicionário. Ou seja, o aluno poderá encontrar subsídios para pesquisa e ampliação do léxico "navegando" pelo dicionário, clicando nos links que lhe chamem a atenção.

Modelo de verbete e recursos previstos:

entrada em português. Definição em italiano de cada conjunto de sememas relativos a cada equivalente em italiano. Equivalente em italiano precedido de sua categoria gramatical. Clicando-se sobre a categoria gramatical, outras informações lingüísticas podem ser obtidas. No caso de substantivos, a flexão de número e de gênero (quando possivel) e os artigos correspondentes. No caso dos verbos, a conjugação e eventualmente a regência. No caso dos adjetivos, a flexão de número e gênero. Sempre que necessário, a definição trará, também, exemplos de contextualização em italiano. Por fim, sinônimos serão eventualmente informados. 
Exemplo de verbete:

blusa 1. camicia da donna di tessuti e modelli diversi. s.f. camicetta: Per andare a lavorare mi sono messa la camicetta di seta e la gonna nera di lana. 2. 2. maglia pesante, spec. di lana, con maniche lunghe, che si indossa per lo più sopra la camicia. s. m. maglione, golf: Fuori nevica. Mettiti il maglione. Sin. blusa de lã. 3. Indumento di tessuto di cotone morbido e peloso all'interno. s.f. felpa: In primavera e in autunno la sera fa sempre un po'freschetto; è meglio portarsi dietro una felpa leggera. D. Sin. moletom. Campo semântico: abbigliamento/vestimentas w.

O formato eletrônico permite que: 1 . ao clicar sobre o campo semântico, o aluno seja dirigido a um conjunto de informaçōes não apenas lingüisticas, mas também culturais relativas ao campo semântico; 2. ícones de áudio encaminhem o aluno à pronúncia da palavra e dos contextos; 3. ícones de vídeo dirijam o consulente a imagens e descrições relativas ao campo semântico, de forma a transformar a consulta de uma única palavra em uma experiência lingüistica e cultural mais ampla. No caso desse verbete, é necessário apresentar ao aluno brasileiro, por meio de imagens e contextos, as diversas possibilidades lexicais equivalentes à unidade blusa: camicetta, blusa, top, maglione, maglioncino, golf, golfino, felpa leggera, felpa pesante, pullover.

Campos específicos são dedicados às colocações, às expressões idiomáticas e aos provérbios.

\section{Conclusão}

Quando falamos do uso de dicionário em sala de aula ou como auxilio para elaboração e compreensão de textos, vem à tona um paradoxo interessante. Se de um lado o professor, adepto da didática moderna, estimula a aprendizagem autônoma de seus alunos, esse mesmo professor condena o uso do dicionário como ferramenta de estudo e de pesquisa.

A valorização do dicionário é completamente diferente entre alunos e professores de um curso de língua estrangeira. Principalmente nos cursos iniciantes, o professor se coloca como o centro do processo para dirimir as dúvidas e acredita que a exposição dos alunos a textos autênticos e/ ou didatizados seja suficiente para que o aluno amplie o seu léxico. Para os alunos, o dicionário é ferramenta de autonomia, nele não só consulta as palavras desconhecidas, mas também verifica se a relação que fez sem o dicionário está correta. O dicionário é a sua segurança, a ponte entre os dois idiomas.

Há metodologias distintas para a elaboração de dicionários voltados para a compreensão e para a produção textual. Quando perguntamos "cosa prendi per colazione?". o aluno brasileiro 
raramente encontrará a resposta nos textos italianos que contêm o mesmo conteúdo semântico (caffelatte, un cappuccino, una brioche), procurará as palavras chocolate, pão, manteiga, leite de soja, queijo, frios, vitamina (leite com frutas) etc. ${ }^{5}$

No momento da produção, interessam ao aluno os equivalentes em italiano das palavras da realidade brasileira e não somente as palavras freqüentes no léxico italiano. Por exemplo, no campo semântico relativo à casa e a seus utensílios não encontramos a unidade lexical rodo, porque não faz parte da cultura e, portanto, nem do léxico italiano. Um dicionário voltado à produção deverá tratar também das palavras que não têm um correspondente em língua italiana e, sendo um dicionário pedagógico, informar a diferença cultural que resulta na não-existência da palavra.

Muitos estudos foram feitos e excelentes resultados foram obtidos no campo da lexicografia bilíngüe e da lexicografia pedagógica. Para o nosso modelo de dicionário, tomamos como base as reflexões do professor Philippe Humblẻ e o produto dessas reflexões, o Dicionário de Aprendizagem Português-Espanhol (Beta) ${ }^{6}$ e o resultado do projeto ELDIT. ${ }^{7}$

A composição da equipe, formada por pesquisadores especialistas em lexicografia bilíngüe italiano-português, contribuirá para agregar os resultados das pesquisas individuais, gerando um produto útil aos aprendizes de italiano como língua estrangeira.

\section{Bibliografia}

ABRAHĀO, Maria Helena Vieira. Metodologia na investigaçăo das crenças. In BARCELOS, Ana Maria Ferreira e ABRAHÃO, Maria Helena Vieira (org.). Crenças e Ensino de Línguas. Foco no professor, no aluno e na formação de professores, Campinas: Pontes, 2006.

BACCIN, Paola Giustina; CARAMORI, Alessandra Paola; COSTA, Ivy Sene; MORETI, Juliana; CORDEIRO, Renata Lira; MENDES, Sergio Ferreira; REVERDITO, Tatiane. Um modelo de dicionário didático italiano-português e português-italiano. Revista de Italianística, São Paulo, p. 204-218, 2004.

BACCIN, Paola Giustina. Proposta di elaborazione di dizionario didattico. Mosaico italiano suplemento da Revista Comunità Italiana, Rio de Janeiro, p. 16-17, 2004.

BACCIN, Paola Giustina; COSTA, Ivy Sene; MORETI, Juliana; MENDES, Sergio Ferreira; CORDEIRO, Renata Lira; ZAMBIANCO, Danila. Para um modelo de dicionário didático: análise contrastiva de alguns dicionários bilíngües. Anais do XI Congresso Internacional de professores de italiano, Foz do Iguaçu: 2005. (no prelo)

BORBA, Herbert Mattei e CARDOSO, Tiago Muller Gil. Desenvolvimento de um dicionário eletrônico de apoio à produção de textos em língua estrangeira. Projeto de conclusão no curso de ciências da computação da Universidade Federal de Santa Catarina. 2003. Disponivel em http://www.inf.ufrgs.br/-tmgcardoso/Relatorio\%20 Final\%20de\%20Projetos\%20II\%20-\%20Herbert\%20e\%20Tiago.pdf (consulta em abril/2008)

BÉJOINT, Henri. Modern lexicography: An introduction. New York: Oxford University Press, 2000.

DURAN, Magali Sanches. Dicionários bilíngües pedagógicos: análises reflexões e propostas. Dissertação de mestrado. Universidade Estadual Paulista. Instituto de Biociências, Letras e Ciências Exatas, São José do Rio Preto: 2004. Orientadora: Profa. Dra. Claudia Maria Xatara.

DURAN, Magali Sanches e XATARA, Claudia Maria. Lexicografia pedagógica: atores e interfaces. DELTA: Documentação de Estudos em Lingüistica Teórica e Aplicada vol.23 n n $^{\circ} 2$ São Paulo, 2007. disponivel em: http://www.scielo. br/scielo.php. (consulta em abril/2008)

5. Conclusões extraídas do trabalho de conclusão de disciplina de pós-graduação da aluna Ana Paula Freitas e apresentadas no Encontro de alunos de pós-graduação em lingüistica (USP, 2006).

6. http://www.dicionario-online.cce.ufsc.br/

7. http://dev.eurac.edu:8081/MakeElditl/Eldit.html 
HUMBLÉ, Phillippe. Melhor do que muitos pensam, quatro dicionários bilingües português - inglês de uso escolar. In: XATARA, Claudia e HUMBLÉ, Philippe (orgs.). Cadernos de Traduçāo.Tradução e lexicolgrafia pedagógica. PGET no 18. Universidade Federal de Santa Catarina, Florianópolis, 2006. p. 253-273.

HUMBLÉ, Phillippe. O discurso do dicionário. Florianópolis, 2007 (no prelo). Disponivel em http://www.pget.ufsc. $\mathrm{br} /$ publicacoes/professores/PhilippeHumble/Philippe_Humble. (consulta em abril/2008)

SANTOS, Maria Gorete Bender. Análise de exemplos no Diccionario Bilingüe de Uso Portugués-español (DIBU). Dissertação de mestrado. Universidade Federal de Santa Catarina, Florianópolis: 2006. Orientador: Prof. Dr. Philippe Humblé.

TARP, Sven. Lexicografia de aprendizes. In: XATARA, Claudia e HUMBLÉ, Philippe (orgs.). Cadernos de Traduçāo. Traduçāo e lexicografia pedagógica. PGET ${ }^{\circ}$ 18. Universidade Federal de Santa Catarina, Florianópolis, 2006. p.295-317.

WELKER, Andréas Herbert. Pesquisas sobre o uso de dicionários para aprendizes. IN: XATARA, Claudia e HUMBLÉ, Philippe (orgs.). Cadernos de Traduçāo.Traduçāo e lexicografia pedagógica. PGET nº 18. Universidade Federal de Santa Catarina, Florianópolis, 2006. p. 175-194.

WELKER, Andréas Herbert e HUMBLÉ. Phillippe. Bibliografia (parcial) da Lexicografia Pedagógica. In: XATARA, Claudia e Humblé, Philippe (orgs.). Cadernos de Traduçāo.Tradução e lexicografia pedagógica. PGET n ${ }^{\circ} 18$. Universidade Federal de Santa Catarina, Florianópolis, 2006. p. 341- 375. 